\title{
First-Year Pharmacy Students Knowledge and Opinions of Residency or Fellowship Training After a Pharm.D.
}

\author{
Sara Amini, Krystal Iheme and Bisrat Hailemeskel* \\ Howard University College of Pharmacy, USA
}

*Corresponding author: Bisrat Hailemeskel, Professor \& Vice Chair, Clinical \& Administrative Pharmacy Sciences, College

of Pharmacy, Howard University, USA

\section{ARTICLE INFO}

Received: 櫘 January 06, 2021

Published: 㓞 February 05, 2021

Citation: Sara Amini, Krystal Iheme, Bisrat Hailemeskel. First-Year Pharmacy Students Knowledge and Opinions of Residency or Fellowship Training After a Pharm.D.. Biomed J Sci \& Tech Res 33(4)2021. BJSTR. MS.ID.005440.

\section{ABSTRACT}

Purpose: To identify and interpret students' ideas and knowledge on residency and fellowship programs.

Methods: A survey was sent via email to 44 first -years professional pharmacy students. The survey had a total of 18 questions. The first eight questions focused primarily on the demographics. The focal point of the remaining seven questions were on students' beliefs and perceptions about residency and a fellowship after completion of pharmacy school. Each participant was asked to answer each question based on a 4-scale Likert scale (strongly agree; somewhat agree; somewhat disagree; strongly disagree).

Results: Among the students surveyed, all 44 students responded with a $100 \%$ response rate. The majority of those who responded to the survey were between the ages of $18-24$. The results showed that the majority of students $(63 \%)$ who took the survey were not familiar with fellowship or residency programs available for pharmacy graduates. However, over $60 \%$ agreed the financial obligations and family commitments would be worth the 1-2 year commitment for either a residency or fellowship program.

Conclusion: Based on this study, it shows that many of the first year pharmacy students had limited knowledge about residency or fellowship programs. However, most of the students believe that completing residency and/or a fellowship after pharmacy school not only would improve their qualifications are a clinician, but that it would also put them in a better position to help patients. Also, most believe that such programs would give them more chances to get better jobs.

\section{Short Communication}

The purpose of this study is to evaluate students' perceptions and opinions about residency and a fellowship after completing pharmacy school. A pharmacy residency is defined as an organized, directed, postgraduate training program in a defined area of pharmacy practice [1]. According to McCarthy, et al. [2], students believed that a key component in their desire to complete residency and a fellowship is based on the idea that these additional opportunities are a prerequisite for certain jobs. However, the perceptions about pressuring residency are not widely discussed during your first year in comparison to a third or fourth-year pharmacy student. Additionally, putting emphasis on a clinical career and educating students on the difference between the two can push more students into pursuing such programs after completing pharmacy school. Many factors and challenges have been described in the current literature that influence the decision of pharmacy students in regard to applying for residency or fellowship training. The research conducted highlighted 251 students across four pharmacy schools in Texas. According to Hickerson, et al. [3], only about one in four pharmacy students choose to pursue a residency program. The online questionnaire surveyed second and third-year students of the four pharmacy schools.

The study has shown different factors that influenced applying for residencies such as increased confidence in practicing pharmacy, helping to achieve career goals, and beliefs in financial guarantee. 
On the other hand, some students believe it would make it more difficult to apply for a residency depending on many factors such as feeling afraid of competition, the lengthy application and interview process [3]. There is very limited literature thatspecifically highlights the opinions and feelings that first-year pharmacy students have about programs after pharmacy school. Much of what is available is geared towards students who are reaching their final years of school. This study was conducted primarily to gauge an audience about topics that are not discussed early on. Also, to understand the level of impact it has on first-year students. The result of this survey will allow students and pharmacy schools an opportunity to implement a possible program that discusses options available to students after completing their pharmacy degree in their first year. This result would aid in increasing students' engagement and possibly pursuing residency or a fellowship. The objective of this study is two folds to:

1) To identity students' opinions about residency or a fellowship and

2) To gather and interpret students' knowledge in regard to residency or a fellowship.

\section{Methodology}

A survey was distributed via email to 44 students at the University of Howard College of Pharmacy. Those surveyed were first-year students of the class of 2024. The survey had a total of 18 questions. The first eight questions focused primarily on the demographics. The focal point of the remaining seven questions were on students' beliefs and perceptions about residency and a fellowship after completion of pharmacy school. Drug Information is a mandatory course for all first-year pharmacy students in which this topic was introduced. The data utilized was collected based on a 4-scale Likert scale (strongly agree; somewhat agree; somewhat disagree; strongly disagree) and created using Qualtrics. The survey was sent to 44 students and 44 students responded $(100 \%$ response rate). A descriptive analysis was then done using SPSS/ SAS software to compute the results (Tables 1 \&2).

Table 1: Response to demographics related questions $(\mathrm{N}=44)$.

\begin{tabular}{|l|c|c|}
\hline & Response Rate (\%) & No. of Response \\
\hline Gender & & \\
\hline$\bullet \quad$ Male & 22.7 & 10 \\
\hline$\bullet$ Female & 77.27 & 34 \\
\hline Age & & 26 \\
\hline$\bullet 18$ - 24 & 59.09 & 18 \\
\hline$\bullet 25$ - 34 & 40.91 & 0 \\
\hline$\bullet 35-44$ & 0 & 0 \\
\hline$\bullet 45$ or older & 0 & \\
\hline $\begin{array}{l}\text { Residence before Coming } \\
\text { to HU }\end{array}$ & & 12 \\
\hline$\bullet$ Maryland & 27.27 & \\
\hline
\end{tabular}

\begin{tabular}{|l|c|c|}
\hline$\bullet$ Virginia & 20.45 & 9 \\
\hline - Other States & 43.18 & 19 \\
\hline
\end{tabular}

Table 2: Response to job related questions $(\mathrm{N}=44)$.

\begin{tabular}{|c|c|c|}
\hline $\begin{array}{l}\text { Have you Worked before } \\
\text { Coming to HU? }\end{array}$ & Response Rate & No. 0 Responses \\
\hline - Yes & 95.45 & 42 \\
\hline - No & 4.55 & 2 \\
\hline \multicolumn{3}{|l|}{$\begin{array}{l}\text { Annual Income if you have } \\
\text { Worked }\end{array}$} \\
\hline - $\$ 10,000$ - $\$ 19,999$ & 16.28 & 7 \\
\hline - $\$ 20,000$ - $\$ 29,999$ & 6.98 & 3 \\
\hline - $\$ 30,000$ - $\$ 39,999$ & 18.6 & 8 \\
\hline - $\$ 40,000$ - $\$ 49,999$ & 6.98 & 3 \\
\hline • >\$49,999 & 11.3 & 5 \\
\hline \multicolumn{3}{|l|}{ Type of Job Held } \\
\hline - Pharmacy Related & 62.79 & 27 \\
\hline $\begin{array}{l}\text { - Non-Pharmacy but health care } \\
\text { related }\end{array}$ & 20.93 & 9 \\
\hline $\begin{array}{l}\text { - No-Pharmacy or Non-Health } \\
\text { care related }\end{array}$ & 16.28 & 7 \\
\hline \multicolumn{3}{|l|}{$\begin{array}{l}\text { Number of Years Worked } \\
\text { before Coming to } \mathrm{HU}\end{array}$} \\
\hline$\bullet<1$ & 16.28 & 7 \\
\hline$\cdot 1-3$ & 32.56 & 14 \\
\hline - 4 - 5 & 25.58 & 11 \\
\hline$\bullet>5$ & 25.58 & 11 \\
\hline \multicolumn{3}{|c|}{ Highest Education Attended before Coming to $\mathrm{HU}$} \\
\hline - Some College & 27.7 & 12 \\
\hline $\begin{array}{l}-2 \text { year degree/associate } \\
\text { degree }\end{array}$ & 4.55 & 2 \\
\hline - 4 year degree & 59.09 & 26 \\
\hline - Professional degree & 9.09 & 4 \\
\hline - Doctorate & 0 & 0 \\
\hline
\end{tabular}

A total of 44 students participated in the survey with a $100 \%$ response rate. Females predominantly represented the presented survey with over 77 percent (77.27\%). Participants were asked their age and resident states. Most were under 35 years old, with majority (59\%) between 18-34 years of age. When asked their state of residence, the majority of them came from states other than the DMV area. About one-quarter (27.27\%) are residents of Maryland, one-fifth (20.45\%) are residents of Virginia. Participants were also asked if they have or previously had a job and the type of job they held prior to joining pharmacy school at Howard University. Students were also asked questions regarding the finances and income. An overwhelming number of students (95.5\%) said they worked before coming to Howard University. When asked what type of job they were working, only one-third said they had a nonpharmacy related job. But the majority of them (62.8\%) had a pharmacy related job. Seven (16.28\%) participants said they had non-pharmacy or non-health care related jobs. 
When asked about their annual income, some $(11.3 \%)$ made over $\$ 50,000$ while others $(16.3 \%)$ made less than $\$ 20,000$. The remaining student $(22.56 \%)$ made between $\$ 20,000$ and $\$ 50,000$. Additionally, more than half of students worked more than four years before coming to Howard University. Over one-quarter (25.6\%) of the participants reported working over 5 years before they joined the pharmacy program. Students were also asked to state their highest education before entering pharmacy school. Most students (59.09\%) have at least a 4 year degree, $27.7 \%$ of students have some college, 4.55\% have an associate degree, and only $9.09 \%$ of students have other professional degrees including a Master of Science degree (Table 3). Based on this survey, the majority of students $(63 \%)$ said that they are not familiar with fellowship or residency programs available for pharmacy graduates. However, about three-quarters $(75.3 \%)$ of the participants believe that having a residency or a fellowship is necessary after completing the Doctor of Pharmacy program.

Table 3: Response to questions related to knowledge and opinions of residency or fellowship training ( $\mathrm{n}=44)$.

\begin{tabular}{|c|c|c|c|c|}
\hline Questions & Strongly Agree & Somewhat Agree & Somewhat Disagree & Disagree \\
\hline $\begin{array}{l}\text { I am very familiar with the fellowship or residency program } \\
\text { available for pharmacy graduates }\end{array}$ & $5(11.4 \%)$ & $13(29.3 \%)$ & $16(36.4 \%)$ & $10(27.7 \%)$ \\
\hline $\begin{array}{l}\text { I believe residency, or a fellowship is necessary after completion of } \\
\text { a Pharm.D. }\end{array}$ & $16(36.7 \%)$ & $17(38.6 \%)$ & $8(18.2 \%)$ & $3(6.8 \%)$ \\
\hline $\begin{array}{l}\text { I believe completing a residency and/or fellowships makes me more } \\
\text { qualified clinician to assist patients }\end{array}$ & $23(52.3 \%)$ & $17(38.6 \%)$ & $4(9.1 \%)$ & $0(0 \%)$ \\
\hline $\begin{array}{l}\text { Even though I support having a residency or fellowship, it is not for } \\
\text { me. }\end{array}$ & $4(9.1 \%)$ & $4(9.1 \%)$ & $18(40.9 \%)$ & $18(40.9 \%)$ \\
\hline $\begin{array}{l}\text { I believe the extra 1-2-year commitment required to do residency or } \\
\text { fellowship after graduation is not a good decision for me financially } \\
\text { or my family commitment. }\end{array}$ & $5(11.4 \%)$ & $11(25 \%)$ & $17(38.6 \%)$ & $11(25 \%)$ \\
\hline $\begin{array}{l}\text { I believe having a residency will give me more opportunity in } \\
\text { choosing my dream job. }\end{array}$ & $25(56.8 \%)$ & $18(40.9 \%)$ & $1(2.3 \%)$ & $0(0 \%)$ \\
\hline $\begin{array}{l}\text { I believe getting a high GPA and work experience to be necessary to } \\
\text { obtain residency or a fellowship }\end{array}$ & $24(54.6 \%)$ & $14(31.8 \%)$ & $5(11.4 \%)$ & $1(2.3 \%)$ \\
\hline
\end{tabular}

When asked if completing a residency or fellowship program makes them a more qualified clinician to assist patients, an overwhelming number (90.9\%) of participants said they agreed and none of them disagreed. What is interesting is that although over $90 \%$ of participants believe that completing a residency or a fellowship is important and necessary, not all of them (81.8\%) are interested in committing themselves to such a program. When they are asked if they believe it to be worth it to them, either financially or their family commitment to spend the extra 1-2-year required to do residency or fellowship after graduation, over sixty percent (63\%) agreed. However, the other one-third (36\%) of participants disagreed. The presented data also shows that except for one participant, all participants strongly agreed or somewhat agreed in the belief that having a residency will give more opportunities in choosing a dream job. Lastly, the majority of the participants (86.4\%) agreed that a higher GPA and work experience is necessary to obtain residency or a fellowship.

\section{Discussion}

Pharmacy is a broad field, and the Doctor of Pharmacy is an entry degree into the profession. Similar to the medical field, the specialty of pharmacy practice is expanding in recent years and is expected to expand even more in the coming years as new diseases and drugs are introduced. In most settings especially a higher level of clinical work is expected, a residency or a fellowship is a requirement for pharmacists. Pharmacy residency can be 1-2 years of training while most fellowship programs require 2 years to complete. The twoyear residency program is usually done as two separate programs. The first year of residency includes generalized training, and in the second year of residency, pharmacy consists of a specific area of interest. In the second year of residency training, which is often times referred to as PGY 2 or second post-graduation year of the residency, trainees choose the specialty as per their interest. Which may include - Ambulatory Care, Critical care, Cardiology, Drug information, Geriatric, Informatics, Nuclear, Nutrition Support, Emergency Medicine, Pediatric, Pharmacotherapy, Psychiatric, and many others.

Not all pharmacy jobs require residency training. For example, those who are planning to work as a community pharmacist, residency rarely requires such training. On the other hand, those who work in an inpatient setting or academia, it is highly advisable to complete a general residency followed by a specialty training. Most residency programs are accredited by the American Health System Pharmacists (ASHP). Fellowship programs are slightly different than residency programs. They are less structured compared to residency programs. Most are not accredited by a major pharmacy society (as most residencies are). In most cases, fellowship programs are two-year programs and usually incorporate some kind of clinical type research. Most of them also include a component of patient care, however the majority are focused on developing expertise in research and scholarship. Majority of fellowship programs are run by the pharmaceutical 
industry. Some programs may also offer a higher degree program along with the fellowship including a Master of Science degree at the end of the training.

The goal of most fellowships is to produce pharmacist-scientists who are capable of independently functioning as a successfully, extramurally funded researcher. Unlike most pharmacists who complete residency training and pursue positions in hospitals or outpatient clinics, those who graduated with a fellowship commonly seek employment usually in academia or industry. In this study, a survey was administered to get the opinion and knowledge of first year professional pharmacy students in relation to residency or fellowship programs. The goal of the study was to collect data which can be useful for universities and pharmacy programs if they need to incorporate some form of training to inform students early in their training to have adequate information to make a well thought decision when they are approaching their final year. The data also indicates that over half of the students disagreed $(59.09 \%)$ on their familiarity with fellowship and residency programs available for pharmacy students. However, it was interesting to see that the majority of students (97.7\%) agreed that residency will give them more opportunities in choosing their dream job. In addition to this, over ninety percent (90.91\%) of students agreed that residency or a fellowship makes them a more qualified clinician to assist patients.

There are a number of considerations that must be weighed prior to pursuing residency of fellowship. Having a residency or fellowship for those who are motivated to engage in job that requires heavy clinical knowledge I considered critical. Although there are number of advantages in having such post-Pharm.D. training, it has also its downside, particularly as a financial loss. The average pharmacist salary in the United States is $\$ 133,263$ as of June 2019. The average salary for a resident pharmacist is $\$ 40,442$ as of July 2019. This tells us that the opportunity cost of choosing residency for one year is $\$ 92,821$. If second year training is pursued, the opportunity cost doubles to $\$ 185,642$. In 2018 , the average pharmacy student graduated with $\$ 166,528$ in student loans with an average interest rate of $6.3 \%$. If loans are placed on hold during residency, the compound interest alone will increase the original loan amount by just over $\$ 10,000$ per year. Despite these numbers, many expert recommend to pursue the residency because it became challenging for students without residencies to get jobs outside of the community pharmacy. Even those community pharmacy jobs prefer and give priority in hiring those with a residency training.

Our data presented in this study shows that many students agreed $(63.64 \%)$ that the extra 1-2-year commitment required to do residency or a fellowship after graduation is worth the investment despite challenges associated with finances or other family obligations. In this study students also asked the challenges of getting a residency or fellowship. The data presented shows that more than four-fifth of students (86.37\%) believe that getting a higher grade average point as an undergraduate and pharmacy related work experience during school is necessary to obtain residency or a fellowship. Despite the limited knowledge the participants have, the study shows, only one-fourth $(25 \%)$ of students agreed that residency and fellowship programs may not necessary after graduating with their Pharm.D. The national rate of residency matching is about $63 \%$. Although Students who pursue residency or fellowship are about half of pharmacy graduates. In our study, the majority of survey participants (81.82\%) agreed they are interested in pursuing residency or fellowship.

\section{Conclusion}

In this study forty-four students participated, it seems that many of them are not familiar with residency or fellowship programs. However, despite the lack of adequate information, the majority of the students believe that completing residency and/or a fellowship after pharmacy school not only would improve their qualifications are a clinician but also puts them in a better position to treat patients. Additionally, most believe that such programs would give them more opportunities for future job prospects. Although more studies are needed, based on the results of this study, it may be advisable to design a program to introduce pharmacy students to the available residency or fellowship programs at an early stage of their training.

\section{References}

1. Residency FAQs.

2. McCarthy B, Weber L (2013) Update on factors motivating pharmacy students to pursue residency and fellowship training: American Journal of Health-System Pharmacy 70(16): 1397-1403.

3. Hickerson SC, Fleming ML, Sawant RV, Ordonez ND, Sansgiry SS (2017) Predicting pharmacy students' intention to apply for a residency: A systematic theory of planned behavior approach 9(1): 12-19.

\section{ISSN: 2574-1241}

DOI: 10.26717/BJSTR.2021.33.005440

Bisrat Hailemeskel. Biomed J Sci \& Tech Res

This work is licensed under Creative Commons Attribution 4.0 License

Submission Link: https://biomedres.us/submit-manuscript.php

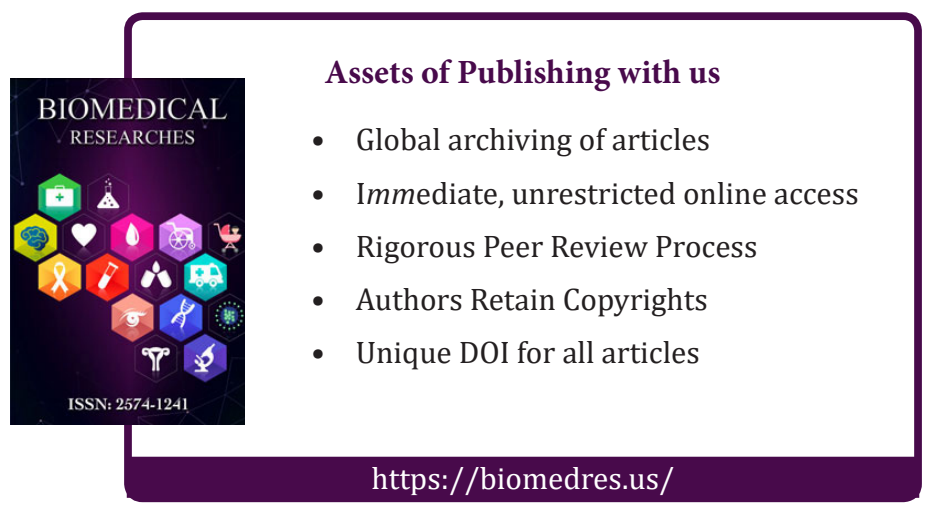

